\title{
Ambivalence about Children in the Family Building Process in Sweden
}

\author{
EVA BERNHARDT \\ Demography Unit, Stockholm University, Sweden \\ FRANCES GOLDSCHEIDER \\ University of Maryland
}

\begin{abstract}
Sweden provides strong support for childbearing and parenthood, including generously subsidized medical, maternal, and child care, paid parental leave, and child allowances. In this context, attitudes towards parenthood are likely to have a particularly strong impact on the decision about whether and when to have children. We examine the links between first births and holding attitudes about children, not just of positive and negative attitudes, but also of ambivalence, namely those who both value children but also value the things that compete with parenthood for young adults' time and other resources. Our analysis shows, measuring attitudes before the transition to parenthood, that ambivalence about childbearing delays the transition to parenthood, but not nearly as much as holding purely negative attitudes. Further, reporting an ambivalent experience from the first child had no significant effect on further childbearing, which testifies to the strong two-child norm in Sweden.
\end{abstract}

Keywords: ambivalence, childbearing, parenthood attitudes

\section{Introduction}

Research on the links between attitudes towards children and subsequent childbearing has mostly focused on single dimensions and relatively simple measures (Fawcett 1988), normally distinguishing those with positive and negative attitudes on one dimension or another (see the review in Bernhardt and Goldscheider 2006). But the social world is rich in ambivalence (Merton 1976), and as in studies of intergenerational ambivalence (e.g., Connidis 2002; Lüscher 1998), it is likely that ambivalence characterizes the attitudes of many young adults when they consider becoming parents. Many may have both strong positive feelings, such as that children give life meaning, confirm adult status, and serve as important objects to love and be loved by, and strong negative feelings, given the great costs of children, both in time and money, that compete with completing higher education and launching professional careers, as well as young adults' ability to pursue other interests important for many in this stage of 
young adulthood, such as travel (Crimmins, Easterlin and Saito, 1991; Fawcett 1988). Raising children has been described as a 'high cost/high reward activity' (Senior 2014, quoting William Doherty).

In Sweden, the greatest cost of children is time, because the state provides important subsidies towards the financial costs of children, including generously subsidized medical, maternal, and child care, paid parental leave, and child allowances. Nevertheless, Sweden has shared with much of the industrialized world in the growth of norms of intensive parenting (Bianchi, Robinson and Milkie 2007, Gauthier 2013), requiring parents to be attentive to the child's needs, to support the child's schooling and everyday activities, to protect against risks of different kinds, and to encourage children's self-confidence (Alwin 1996; Björnberg and Kollind 2005), greatly increasing the time costs of children. With the new ideologies of how to raise and care for a child, parallel with increased pressure on men and women in paid employment, ambivalence about parenthood is likely to have become a more important phenomenon in contemporary societies (Bergnéhr and Bernhardt 2013). Because of postponing childbearing to higher ages, today many potential parents have had more time to become acutely aware of the freedoms they are giving up (Senior 2014).

The main purpose of this study is to examine the links between attitudes towards children and the transition to parenthood, both positive and negative attitudes as well as ambivalent attitudes, using recent longitudinal data on young adults in Sweden that provide measures of attitudes towards children obtained prior to the transition to parenthood (The Young Adult Panel Study, YAPS). We will examine these relationships both for the timing of the transition to parenthood (as well as on later transitions). We will also consider differences between men and women (given women's greater time investments in children, even in Sweden); among those of different ages (as older individuals may have already experienced travel and other opportunities cherished by young adults, and be more firmly established in their occupational careers); and between the more educated (who are likely to have high consumption aspirations) and the less educated.

\section{Background}

The transition to parenthood in contemporary Western societies normally takes place relatively late in the transition to adulthood, the final step, as it were. Adulthood was once considered to begin with the end of education, at least in the mid-twentieth century, by which time, and particularly with the advent of the necessity for post-high school education, school attendence had begun to encroach on adult ages and the end of education was followed rapidly by employment (for men), marriage and parenthood (Modell, Hirschberg, and Furstenberg 1976). In the past several decades, however, difficulties young people increasingly face in the labor market and the complex of 
behaviours that have led to the deferral of committed relationships with partners and children, together with the continued upward pressure on educational attainment, have led to the creation of a new life course stage which has been called "emerging adulthood" (Arnett 2007).

The transition to adulthood is thus defined by a multitude of transition events, often quite widely spaced. More specifically, the research area can be divided into studies of the school-to-work transition on the one hand and family formation on the other (Buchmann and Kriesi 2011). The sequence of the key events (leaving home, finishing school, getting a job, union formation, transition to parenthood) and the duration between them is of course of considerable interest, as are the norms about at what age these events should take place (Liefbroer and Billari 2009). The Nordic countries are characterized by extremely early home leaving and very late timing of entry into parenthood, and consequently a long period of childless, non-family living as young adults. Buchmann and Kriesi (2011) argue that these circumstances are due to a cultural legacy of the individual's priority over the family, which is strengthened by welfare rights and benefits granted as individual entitlements.

While entry into parenthood is often regarded by researchers as one of the important markers of the transition to adulthood (Liefbroer and Toulemon 2010), in the minds of young people today it may not be a necessary condition for adulthood. The views of young adults in Sweden regarding the importance of leaving the parental home, having a co-residential partner, becoming a parent, and being able to support oneself economically as conditions for being regarded as an 'adult', were investigated by a set of questions in the 1999 wave of the Young Adult Panel Study. In the minds of young adults it is clearly the latter, i.e. the ability to support oneself economically, that is by far the most important; evidently supporting others is not part of their view of adulthood. About half of the childless respondents did not agree at all with statements about the importance of family transitions, i.e. having a partner and becoming a parent. And there were no noticeable differences between men or women, or between those with egalitarian and non-egalitarian gender attitudes (data not shown). While most young men and women in Sweden seem to regard parenthood as 'a natural step to take' in the course of their lives (Bergnéhr 2010), they apparently regard themselves as adults long before they are ready to take on responsibilities for others by becoming parents. Thus 'emerging adulthood' is a new life course stage between adolescence and full adulthood that bridges the ages between 18 and 30, when individuals are no longer children, because they are self-supporting, but not yet responsible adults (Arnett 2007; Furstenberg 2012). During these ages, many are still pursuing education and/or have not established stable work and family careers. Increasingly, young adults see these ages as a time to travel, experiment, and explore, requiring freedoms not normally found in conjunction with the restrictions of parenthood. Increasing difficulties of getting a permanent job (Mills and Blossfeld 2005) may also prolong the period of 'emerging adulthood'. 
Most young adults continue to want to become parents, not just as a signal of (finally) achieving adulthood, but also as a sign that the period of free exploration is over, and that stability can be achieved. During the early years of emerging adulthood, however, children represent a decidedly mixed blessing. How soon is too soon to be tied down? How late can they/should they wait? Further, another characteristic of emerging adulthood is increasing heterogeneity (Furstenburg 2012), so that many may value the freedoms children preclude, while others reach quickly for the comfort and security of a more stable life style. And of course, it is likely that many will feel both, and be ambivalent about becoming parents (and others may have little interest either in freedom or family stability).

In a study of the ambivalence about parenthood among young adults in Sweden, Bergnéhr and Bernhardt (2013) showed that the majority of those still childless had positive expectations of parenthood entailing a more meaningful life, but also that many anticipate that becoming a parent will mean less personal freedom. About 25 percent of the respondents expressed 'ambivalence,' in the sense that they expected both a more meaningful life and less personal freedom. As a child is highly likely to restrict parents in a society where independence is a highly valued characteristic of life (Bauman 2003; Lee 2005), the authors argue that to expect less personal freedom in most cases carries a negative connotation, while it is hard to dispute that a more meaningful life is considered as something positive. Focus group interviews provided some evidence on how young men and women reason about the implications that having a child would have on their life (Bergnéhr and Bernhardt 2013). Individual freedom came across as being a highly valued aspect of life and as a major reason for deferring parenthood. They want to be responsible parents, and a responsible parent is ready to live a child-centered life (Bergnéhr 2010). The participants in the focus groups particularly emphasized less time and energy for one's own hobbies and interests, for educational aspirations and strengthening the relationship with the partner, and an overall more immobile life, given the expected strains of parenthood. On the other hand, the most frequently mentioned benefits associated with having a child were a new life with new experiences, a new member of the family to love, and the child as a person who ties generations and people together.

Quantitative analysis of Swedish survey data showed that males were significantly more likely to be characterized as ambivalent than females, while post-secondary education increased the likelihood that the respondent reported ambivalent feelings about parenthood. Living with a partner seemed crucial to reducing ambivalent feelings among men, while there was no gender difference in the effect of higher education. Interestingly enough, those expressing ambivalent views about having children were only slightly less likely to expect a child within the next five years, compared to those positively inclined. In the current paper, we test this result in order to see whether ambivalence has a stronger effect on the actual transition to parenthood and on the births of subsequent children than it did on Swedish young adults' intentions regarding future childbearing. 
The Theory of Reasoned Action and Planned Behaviour (Ajzen 1991; Moors 1997) supports an hypotheses that positive/negative attitudes toward parenthood should increase/decrease the likelihood of a birth actually occuring. However, it is not clear what it predicts when one considers contradictory attitudes, i.e. holding both positive and negative attitudes, which is likely to create ambivalence. Attitudes influence behaviour via intentions, but are modified by 'behavioural controls'. Thus, behavioural achievement (in this case actually becoming a parent) depends jointly on motivation (intention) and ability (behavioural control). From a sociological point of view, intentions can be defined as proxies of future anticipated behaviour (Moors and Bernhardt 2012), and hence as alternative dependent variables (and are often used in this way). However, in this paper we prefer to model actual events (the birth of a child) rather than intentions. Moreover, we have the advantage of measuring attitudes before the actual family transition has occurred, which is necessary to be able to draw conclusions about the direction of the relationship (Lesthaeghe and Moors 2002).

How then do attitudes towards the costs and benefits of children affect the timing of the transition to parenthood? It is easy to predict that those with the strongest concerns about children limiting freedom will delay the longest, while those who value the rewards that children tend to bring to daily life will become parents early; much research has shown this (e.g., Bernhardt and Goldscheider 2006), but what of the ambivalent? Will they delay as well? Our first hypothesis is that they will be intermediate in their timing of parenthood between those with positive and negative attitudes.

Testing this hypothesis in Sweden adds particular saliance, as Sweden is considered to be a country with relatively low levels of familism. Swedes are considered to have relatively weak intergenerational ties (Newman 2012; Reher 2005) and to be far along on the Second Demographic Transition and hence high on the need for selfactualization (Lesthaeghe 2010). Despite a strong two-child norm (two is the desired number of children for over 60 percent of childless young adults in Sweden, both men and women, own calculations from YAPS data), it seems possible that many young Swedes will allow their ambivalence to delay for quite a long time.

Sweden is also a highly egalitarian society in terms of socioeconomic status. This suggests that unlike in the US, where class heterogeneity is linked with extreme heterogeneity in the timing of parenthood (Martin 2004), even less educated Swedes should resemble more educated Swedes in the relationships between positive, negative, and ambivalent attitudes towards parenthood and subsequent births. Hence, we hypothesize that class will not distinguish these relationships.

Gender, in contrast, is likely to make a strong difference, even if gender differences in the timing events in the transition to adulthood are more muted in Sweden than in other European countries (Liefbroer and Goldscheider 2007). On the one hand, children limit women's freedoms more than men's but on the other, women tend to invest more in the 
parental role than men, taking the majority of parental leave (Duvander and Andersson 2006; Oláh and Bernhardt 2008) and being much more likely to work part time when children are young (Sundström 1991). Hence, we expect that for most couples, it will be the female partners whose attitudes dominate, which means that attitudes towards children will have more impact on women's family building than on men's.

Age might also make a considerable difference in the links between ambivalent feelings about children and the transition to parenthood. By the late 20s, most young Swedes are likely to have had the opportunity to travel, and to experiment with different experiences and relationships. This suggests a final hypothesis, that the effect of ambivalent attitudes might attenuate with age.

In this paper, we model the transition to first births using comparable models for each sex, age, and educational group, including measures of attitudes towards parenthood. Taking advantage of longitudinal data from the YAPS database, we construct indicators of attitudes about the transition to parenthood, measured while the respondents were childless, and use them to predict the transition to first parity over the ensuing six years. We will also analyze how parenthood attitudes reported after the transition to parenthood i.e., attitudes shaped by actually experiencing positive and negative consequences of becoming parents, affect continued childbearing. The analysis of later transitions estimates the links between attitudes towards the costs and benefits of children registered in 2003 among those who became parents relatively young (between 1999 and 2003) and childbearing between 2003 and 2008.

\section{Data and methods}

Data: The Young Adult Panel Study (YAPS) was created to enable studies of the complex interrelationships between attitudes and demographic behaviour (see www. suda.su.se/yaps). Designed from the beginning to be longitudinal, there have been three waves of survey data collection, carried out in 1999, 2003, and 2009, thus spanning a ten-year period. The survey data have been combined with register data from the mid-1980s onwards, including births up to 2008 .

Sample: The original target sample in 1999 consisted of 4,360 Swedish-born persons in 1968, 1972 and 1976. This resulted in 2,820 respondents (response rate of 65 percent). Information about their identities have been kept by Statistics Sweden through 2009. For the 2003 round of the survey, a new group $(1,194)$ of 22 -year olds (the 1980 cohort) was added, increasing the number of birth cohorts to four, with an overall response rate of 70 percent. At the time of the survey in 2003 the respondents were $22,26,30$, and 34 years old, respectively. The analytic sample used in this paper for the analysis of the transition to parenthood consists of the 1,567 respondents 
who were childless at the time of the 2003 survey., Because the median age at first birth for women in Sweden is close to 30, and even higher for men, clearly this kind of sample introduces some problems with left censoring. Table 1 shows percentage childless among the respondents by age and sex. In particular for those aged 30 or 34 (and more so for men than for women) substantial proportions are not included in our sample because they have already become parents.

Table 1. Percent childless respondents by age and sex.

\begin{tabular}{lccccc}
\hline & \multicolumn{5}{c}{ Age in 2003 } \\
& 22 & 26 & 30 & 34 & Total \\
\hline Men & 95.8 & 84.2 & 59.1 & 31.0 & 68.7 \\
Women & 91.3 & 76.3 & 43.1 & 19.6 & 59.9
\end{tabular}

Variables. Among the many attitudinal questions included in the survey questionnaire, one set focused on parenthood attitudes. Childless respondents were asked to indicate, on a scale from 1 to 5 , whether they expected less personal freedom, economic problems, less time for friends, a better partner relationship, and/or a more meaningful life as a result of becoming a parent ["Becoming a parent can influence one's life in many ways. What is your view? If (when) I get children .....I can no longer do what I want..., My life will become more meaningful etc"]. An earlier analysis of the parenthood attitudes among childless young adults in Sweden (Bernhardt 2004) has shown that among the three items indicating (likely) negative consequences of parenthood (less personal freedom, economic problems, less time for friends) it is the first item that is of the most concern to the respondents; i.e., it is the statement which the respondents are most likely to agree with, while similarly, 'a more meaningful life' seemed more influential than the expectation of a better partner relationship. We will therefore focus on those two in our analysis of the effect of prior parenthood attitudes on the transition to a first birth among childless young adults in Sweden. We will use information for a sample of 1,567 respondents who were childless in at the time of the survey in 2003 (801 women and $767 \mathrm{men}$ ). We follow the respondents until they have experienced the event of a live birth (the outcome variable) or 2009, when the analysis ends.

Although expecting both less personal freedom and a more meaningful life is not necessarily contradictory, it can be assumed that holding both these views is likely to create some ambivalence about making the transition to parenthood. We have therefore constructed a four-category variable in the following way:

1. Ambivalent. Have indicated 4 or 5 on the scale (1-5) regarding both 'loss of personal freedom' and 'increasing meaningfulness'

2. Positively inclined. Have a high value on 'increasing meaningfulness' and a low (1-3) on 'loss of personal freedom' 
3. Negatively inclined. The reverse

4. Indifferent. Have values less than 4 on both 'loss of personal freedom' and increasing meaningfulness'

The percentage distributions of the parenthood attitude variable for men and women, as well as their distributions on the other measures we include in this analysis, are shown in Table 1. Roughly 30 percent of both men and women are defined as 'positively inclined', and about 20 percent as 'negatively inclined' (with men slightly less positive and slightly more negative than women). The major difference between men and women is that men are much more likely to be 'ambivalent' while more women fall in the 'indifferent' category (neither expecting less personal freedom nor a more meaningful life).

Table 2. Percentage distributions. Childless young adults in Sweden.

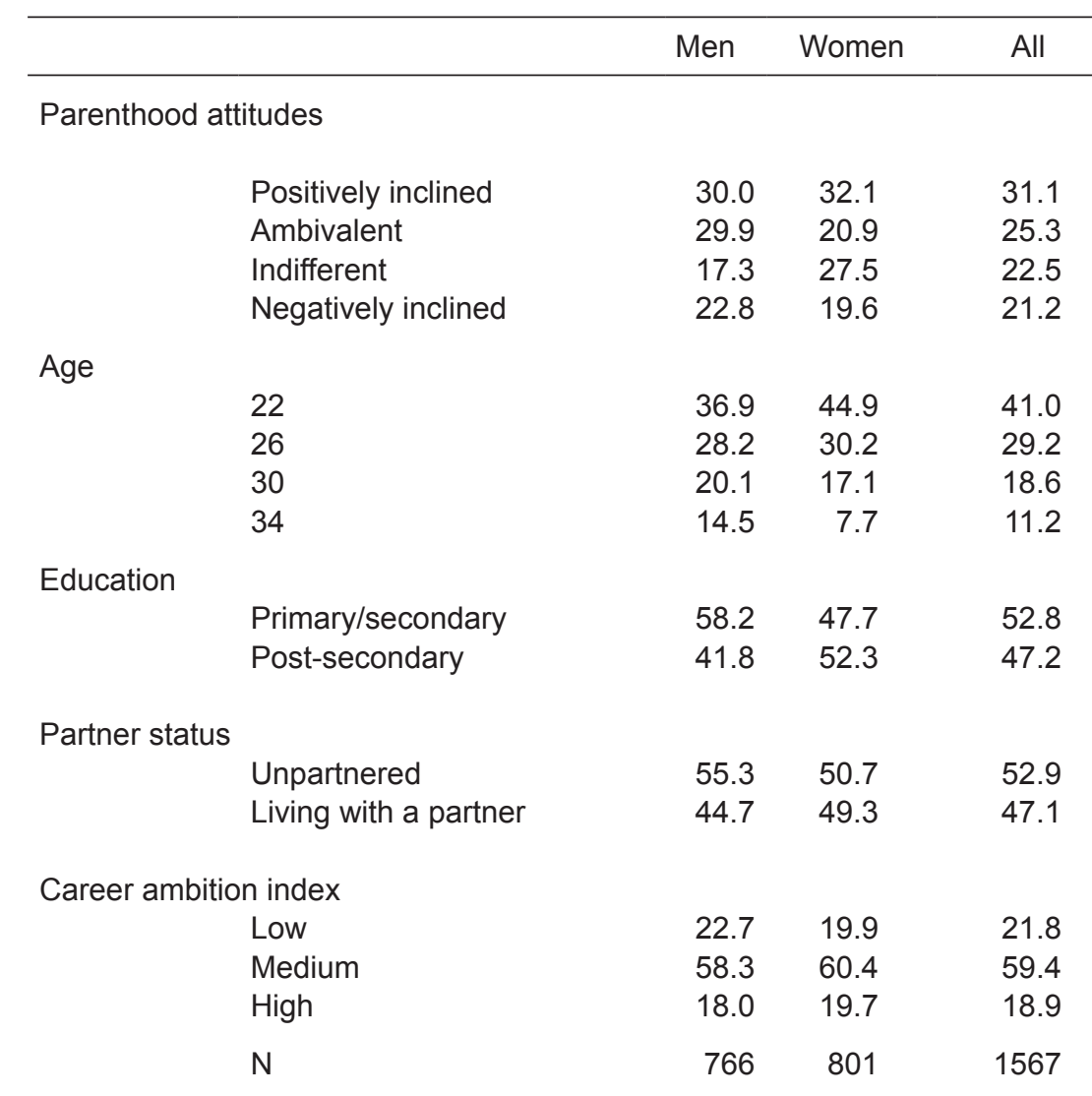

In addition to our main explanatory variable (parenthood attitudes), we also include controls for age of the respondent (22, 26, 30 and 34), education (primary/secondary versus post-secondary), co-residential partner status (unpartnered or living with a cohabiting or married partner) and a career ambition index (low, medium, high). All 
these variables are measured at the time of the 2003 survey. Clearly, partner status can change over time, as those unpartnered start cohabiting or get married, or those living with a partner break up their current co-residential relationship. However, we have not included time-varying covariates in our analysis.

We included the measure of career ambition in order to capture possible delay between wanting to be well established in one's career/working life and taking on the responsibilities of a child. The index was constructed using the following items in the questionnaire: 1) How important is work in your life, 2) How important is it in your life to be successful at your work, 3) A good job offers good opportunities to advance, and 4) A good job means that I get a high salary and/or other benefits. Adding the four items gave a sum from 4 to 20 . Cronbach's alpha for the index was 0.6484 , which is reasonable given the limited number of items included. However, as the scale was heavily skewed to the right, indicating that young Swedes report high levels of career orientation, we split the variable into three categories: low $=4-13$, medium $=14-17$, and high $=18-20)$. We assume that the respondent's career ambition as well as his/ her parenthood attitudes remain more or less stable over this relatively short time period (until the birth of the first child or until the end of the observation period, i.e. a maximum of six years).

Method: The transition to a first child is analysed with Cox regression, using register information on live births between 2003 and 2008. The observation period starts at the time of the 2003 survey round. We realize that this produces variable lengths of left censoring for the various cohorts, but when we repeated the models for the separate cohorts, there was little difference in the patterns of results, with the exceptions discussed below.

\section{Results}

Our major findings for the analysis of the transition to parenthood are presented in Table 2. The first column ('All') shows the results for the total population of childless young adults. Those with positive attitudes towards children are the most likely to have made the transition to parenthood over the study period; all the other combinations have significantly lower odds of making this transition (although the result for the ambivalent was only significant at .10). Those with negative attitudes were barely half as likely to make the transition as those with positive attitudes (.49), while the indifferent made the transition only about $70 \%$ as rapidly. The ambivalent were nearly as likely to make the transition to parenthood as those with positive attitudes $(82 \%)$. 
Table 3. Effects of parenthood attitudes on first births among childless respondents in 2003, all, men and women (hazard ratios).

\begin{tabular}{llll}
\hline & All & Men & Women \\
\hline Variables & & & \\
\hline Parenthood attitudes & & & \\
Positive & 1.00 & 1.00 & 1.00 \\
Ambivalent & $\left.0.82^{*}\right)$ & 0.91 & 0.79 \\
Indifferent & $0.69^{* *}$ & 0.79 & $0.63^{* *}$ \\
Negative & $0.49^{* * *}$ & $0.68^{*}$ & $0.37^{* * *}$ \\
Female vs male & $1.27^{* *}$ & & \\
Age & & & \\
22 & $0.46^{* * *}$ & $0.49^{* * *}$ & $0.45^{\star * *}$ \\
26 & 1.00 & 1.00 & 1.00 \\
30 & 1.16 & $1.38^{*}$ & 1.04 \\
34 & $0.46^{* * *}$ & $0.43^{* * *}$ & $0.53^{*}$ \\
Primary/secondary education & 1.00 & 1.00 & 1.00 \\
Post-secondary education & 1.05 & 0.97 & 1.14 \\
Low career ambition & 0.90 & 1.00 & 0.82 \\
Medium career ambition & 1.00 & 1.00 & 1.00 \\
High career ambition & 0.96 & 1.25 & 0.80 \\
Unpartnered & 1.00 & 1.00 & 1.00 \\
Living with a partner & $3.45^{\star * *}$ & $3.86^{* * *}$ & $3.21^{* * *}$ \\
N & 1567 & 766 & 801 \\
Log likelihood & -3128.33 & -1326.02 & -1674.87 \\
& & &
\end{tabular}

We also assessed these relationships changing the reference category for parenthood attitudes to negative. This allowed us to test whether there were differences among the three groups that did not have simple, positive attitudes. This analysis indicated that both the ambivalent and the indifferent were significantly more likely to make the transition to parenthood than those with negative attitudes (results not presented).

The controls mostly showed the expected relationships. Women made the transition to parenthood more rapidly than men, and those living with a partner were far more likely to become parents than those who were not in a residential partnership. The age pattern suggests a curvilinear pattern, with those aged 26 (the reference category) and 30 in 2003 being the most likely to become parents, those younger still delaying, and those who had delayed well into their 30s now unlikely to change their ways. Educational level and career ambition showed no significant relationships.

This table also shows how the results for the total differ between men and women (cols. 2 and 3). The results indicate that indeed, the relationship between attitudes and childbearing are considerably stronger for women than for men. For each contrast, the relationship for women appears to be stronger than that for men, both in terms of 
the strength and significance of the relationships, although for each, given the smaller sample, the ambivalent are not significantly different from the positive. In contrast, there are no substantive differences by gender in the links between the controls and childbearing (though high career ambition might show a significant gender interaction, showing the lingering effects of traditional relationships in Sweden).

We also examined differences in the links between parenthood attitudes and childbearing by education (post-secondary vs. less than post-secondary) and age. Although we had expected to find little difference by education, in fact there was one: holding ambivalent attitudes on the transition to parenthood was significantly related only for those with less education (results not presented). Among those with a post-secondary education, there was no difference between the ambivalent and the positive (odds ratio of .99). In contrast, among the less educated, the ambivalent were only two-thirds as likely to have made the transition to parenthood as those with positive attitudes. It may be that, with fewer resources, these young adults had not been able to afford the explorations that were possible for those with more resources; it might also be that for those with fewer resources, parenthood is more limiting than it is for those who can afford babysitting for evening activities, travel with children, and other activities popular with young adults. Hence, although ambivalence is more common among the more educated (Bergnéhr and Bernhardt 2013), it is more consequential among the less educated.

In our analyses for each of the separate age groups, as we expected, ambivalent feelings had their greatest impact on the youngest respondents, and attenuated with each older age (results not presented). In contrast, those with negative attitudes were less likely to make the transition to parenthood at every age than were those with positive attitudes.

\section{Later transitions}

We pursued our analysis of the effect of ambivalence on childbearing by investigating how reporting an ambivalent experience with the first child affects the transition to a second (or a third) child. Positive attitudes increased greatly after the transition to parenthood (from 32 to 62 percent for women, and from 30 to 48 percent for men), but ambivalence increased as well (from 21 to 29 percent for women, and from 30 to 41 percent for men). Hence our combined parenthood attitude variable had three categories: ambivalent, positive, and negative/indifferent. Nevertheless, reporting an ambivalent experience from the first child had no significant effect on further childbearing (neither second nor third birth, results not shown). Apparently, the strong two-child norm in Sweden is powerful enough to overcome any less than positive experience of becoming a parent.

However, unlike the finding from the analysis of the transition to parenthood, career ambition had a negative effect for women's continued childbearing. As this effect was found for second but not for third births, we concluded that the negative effect seen for 
the second child was merely the result of a wider spacing between one and two, suggesting that a longer birth interval is easier to fit into the life course of a career woman.

\section{Discussion}

In this paper, we analyzed the role of attitudes towards children in the family building process in Sweden, a country with near-replacement fertility and strong support for families. Using longitudinal data spanning a period of six years, we measured the links between attitudes held prior to the beginning of childbearing and the transition to parenthood and subsequent family building. We distinguished holding positive and negative attitudes from ambivalent (and indifferent) attitudes. Our results show that in the first decade of the $21^{\text {st }}$ century, the majority of young Swedes hold positive attitudes about the value of parenthood in their lives, and most of them also make the transition to parenthood. Even those with great concerns about the time costs to their freedom of children nevertheless make the transition to parenthood nearly as quickly as those with decidedly positive attitudes. The minority who see little value to parenthood, in contrast, are much more likely to delay, especially if they are also concerned about how children restrict their freedom. Thus, although a substantial minority of childless young adults express ambivalent attitudes toward having children, this ambivalence seems to have only minor impact on the actual transition to parenthood (and even less on later transitions).

These relationships are structured somewhat differently among those of different ages and educational levels, as well as between men and women. These attitudes have more effect on women's transition to parenthood than they do on men's, possibly reflecting women's greater engagement in parenting, and their relationships attenuate with age as young people have increasingly realized their experiential goals for emerging adulthood as well as their career ambitions. Ambivalence about childbearing delays parenthood more among those with lower educational attainment than those with more, suggesting that young Swedes of all educational levels share aspirations for non-family experiences in young adulthood, but that only those with more resources are able to realize them. Interestingly enough, reporting an ambivalent experience after the birth of the first child did not have any significant effect on continued childbearing, suggesting that the strong two-child norm in Sweden is powerful enough to overcome such less than positive feelings.

These results make an important contribution to studies of the effects of attitudes on fertility. They make clear that at least under some conditions, it is not enough simply to distinguish those with more positive from those with more negative attitudes towards children; it is also important to consider that ambivalent attitudes towards children have some impact on the transition to parenthood. Nevertheless, overall, it 
seems that the dominent attitude shaping the timing of the transition to parenthood is holding positive views of children.

Other strengths of this analysis include 1) the systematic use of longitudinal data, so that information on parental attitudes, collected prospectively, can be examined in terms of fertility measured afterwards; 2) the careful distinguishing of positive, negative, and ambivalent attitudes, and 3) distinguishing the transition to parenthood (i.e., first births), from later family building. Even the use of Sweden is a strength, because although the state offsets much of the financial costs of children, the time costs are substantial, as in most other developed countries.

In addition to its focus on a single country, the analysis has several weaknesses. The sample is small, and about half of the respondents in the 2003 survey had already become parents. Moreover, many of these young adults still have additional childbearing years in which to continue their family building, and those who begin quite late might differ substantially from those studied here. Moreover, there is no information on the actual attitudes of the partner (if any). The ideal model would include the attitudes of both partners, measured before children are born, to best understand their joint transition to parenthood (regarding the importance of couples' joint decisionmaking with regard to childbearing see Thomson and Hoem 1998 as well as Stein, Willen and Pavetic 2014).

Clearly, this analysis needs replicating in different contexts. It may be that attitudes have their greatest impact in the absence of the other supports, as in Italy or the United States, so that Sweden's extensive state policies that allow workers to care for families (Oláh and Bernhardt 2008) might reduce variation in the family building process, making attitudes less relevant. Our paper is an important first step in attempting to clearly elucidate the ways in which attitudes towards the new demands of parenthood are affecting the timing of beginning childbearing in Sweden, and perhaps elsewhere, as well. 


\section{References}

Ajzen, I. (1991). The theory of planned behavior. Organizational behavior and human decision processes 50(2): 179-211.

Alwin, F. D. (1996). From childbearing to childrearing: the link between declines in fertility and changes in the socialization of children. Population and Development Review 22: 176-196.

Arnett, J.J. (2007). Emerging adulthood: What is it and what is it good for? Child Development Perspectives 1:68-73.

Bauman, Z. (2003). Liquid love: On the Frailty of Human Bonds. Cambridge: Polity.

Bergnéhr, D. (2010). En bra förälder (A good parent). Locus 4: 30-49.

Bergnéhr, D. and Bernhardt, E. (2013). The non-modern child? Ambivalence about parenthood among young adults in Sweden. In Ellingsaeter and Jensen (eds). The Social Meaning of Children and Fertility Change in Europe, pp.102-119. Routledge.

Bernhardt, E. (2004). Att bli förälder- unga vuxnas föreställningar. Välfärd 2004:2, Statistics Sweden. [To become a parent - the perceptions of young adults]

Bernhardt, E. and Goldscheider, F. (2006). Gender equality, parenthood attitudes, and first births in Sweden. Vienna Yearbook of Population Research, 19-39.

Bianchi, S., Robinson, J. and Milkie, M. (2007). Changing Rhythms of Family Life. New York: Russell Sage.

Björnberg, U. and Kollind, A-K. (2005). Individualism and Families: Equality, Autonomy and Togetherness. London: Routledge.Björnberg,

Buchmann, M.C. and Kriesi, I. (2011). The transition to adulthood in Europe. Annual Review of Sociology 37: 481-503.

Connidis, A. (2002). Sociological ambivalence and family ties: A critical perspective. Journal of Marriage and Family 64(3): 558-567.

Crimmens, E., Easterlin, R. and Y. Saito, Y. (1991). Preference changes among American youth: Family, work, and goods aspirations, 1976-1986. Population and Development Review 17: 115-133.

Duvander, A-Z. and Andersson, G. 2006. Gender equality and fertility in Sweden. Marriage and Family Review 39(1): 121-142.

Fawcett, J. T. (1988). The value of children and the transition to parenthood. Marriage \& Family Review 12(3-4), 11-34.

Furstenberg, F. (2012). Inequality and The Transition to Adulthood: Toward A Comparative Approach. Paper presented at the annual meetings of the Population Association of America.

Gauthier, A. (2013). Social Class and Parental Investment in Children. Unpublished manuscript.

Lee, N. (2005). Childhood and HumanValue: Development, Separation and Separability. Maidenhead, Berkshire: Open University Press.

Lesthaeghe, R. (2010). The unfolding story of the second demographic transition. Population and Development Review 36:211-251.

Lesthaeghe, R. and Moors, G. (2002). Life course transitions and value orientations: 
Selection and adaptation. In Lestaeghe, R. (ed.) Meaning and Choice: Value Orientations and Life Course Decisions. pp. 1-44. The Hague and Brussels: NIDI CBGS Publication.

Liefbroer, A. and Billari, F.C. (2009). Bringing norms back in: A theoretical and empirical discussion of their importance for understanding demographic behaviour. Population, Space, and Place 16:287-305.

Liefbroer, A. and Goldscheider, F. (2007). Transitions to adulthood? How unique is Sweden in the European context? In Bernhardt, E., Goldscheider, F., Goldscheider, G. and Bjeren, G. (eds.) Immigration, Gender, and Family Transitions to Adulthood in Sweden, pp. 203-227. New York: University Press of America.

Liefbroer, A. and Toulemon, L. (2010). Demographic perspectives on the transition to adulthood: An introduction. Advances in Life Course Research 53-56.

Lüscher, K. (1998). Intergenerational ambivalence: A new approach to the study of parent-child relations in later life. Journal of Marriage and Family 60:413-425.

Martin, S. P. (2004). Delayed Marriage and Childbearing: Implications and Measurement of Diverging Trends in Family Timing. Pages 79-119 in Social Inequality, edited by Kathryn Neckerman. New York: Russell Sage.

Merton, R.K. (1976). Sociological Ambivalence and Other Essays. New York: Free Press.

Mills, M. and Blossfeld, H-P. (2005). Globalization, uncertainty and the early life course: A theoretical framework. In Blossfeld et al. (eds.). Globalization, Uncertainty and Youth in Society: The Losers in a Globalizing World. Routledge.

Moors, G. (1997). The Dynamics of Values-Based Selection and Values Adaptation. Vrije Universiteit Brussel IPD-Working Paper 1997-4.

Moors, G. and Bernhardt, E. (2009).Splitting up or getting married? Competing risk analysis of transitions among cohabiting couples in Sweden. Acta Sociologica 52: 227-247.

Newman, K.S. (2012). The Accordian Family: Boomerang Kids, Anxious Parents, and the Private Toll of Global Competition. Boston: Beacon Press.

Oláh, L. and Bernhardt, E. (2008). Sweden: Combining childbearing and gender equality. In T. Frejka et al (eds.): Childbearing Trends and Policies. Rostock: Max Planck Institute for Demographic Research.

Reher, D. S. (2005). Family Ties in Western Europe. Persistent contrasts. In Strong Family and Low Fertility: A Paradox? European Studies of Population, Vol. 14.

Senior, J. (2014). All Joy and No Fun. The Paradox of Modern Parenthood. New York: HarperCollins.

Sundström, M. (1991). Part-time work in Sweden: Trends and equality effects. Journal of Economic Issues 25(1): 167-178.

Stein, P., Willen, S. and Pavetic, M. (2014). Couples' fertility decision-making. Demographic Research vol. 30, article 63. DOI: 10.4054/DemRes.2014.30.63.

Thomson, E, and Hoem, J. (1998). Couple childbearing plans and births in Sweden. Demography 35(3): 315-322. 